\title{
Power and Positivity: Psycholinguistic Perspectives on Word Valence in Canadian Parliament
}

\author{
Jordan Gallant and Gary Libben * \\ Department of Applied Linguistics, Brock University, St. Catharines, ON, Canada
}

\section{OPEN ACCESS}

Edited by:

Mila Vulchanova

Norwegian University of Science and

Technology, Norway

Reviewed by:

Pilar Ferré Romeu,

University of Rovira i Virgili, Spain

$X u X u$,

Shanghai Jiao Tong University, China

Kristian Tylén,

Aarhus University, Denmark

*Correspondence: Gary Libben glibben@brocku.ca

Specialty section:

This article was submitted to

Language Sciences,

a section of the journal

Frontiers in Communication

Received: 03 September 2021

Accepted: 19 October 2021

Published: 09 November 2021

Citation:

Gallant J and Libben G (2021) Power and Positivity: Psycholinguistic Perspectives on Word Valence in

Canadian Parliament.

Front. Commun. 6:770497.

doi: 10.3389/fcomm.2021.770497
Politicians are skilled language users who deploy words strategically and pay close attention to the emotions that those words evoke. We examined the emotional characteristics of over 92 million words spoken by Canadian Members of Parliament between 2006 and 2021. The analysis brought together the Warriner, Kuperman, and Brysbaert (Behav. Res., 2013, 45, 1191-1207) database of valence (positivity) ratings for English and the Canadian Hansard, which contains a transcription of parliamentary speech. Results revealed that the positivity of words used by politicians in parliament was significantly related to both political and social variables. Politicians increased the positivity of their language after the onset of the COVID-19 crisis. Within the time of the crisis, word positivity was linked statistically to month-by-month case counts, indicating a very fine-grained sensitivity to social realities. Our analysis also revealed a fine-grained sensitivity of word valence to political realities. As expected, parties in power used more positive language than those in opposition. In addition, our analysis revealed that individual parties have characteristic levels of word positivity and that those levels change in accordance with political changes as specific as whether or not the party in power holds a majority of seats in parliament. These findings suggest that the emotional properties of words used by Members of Parliament are reliably indexed to sociopolitical dynamics. The findings also suggest that the methodology of linking individual word ratings to Hansard Documents (which are used to document Parliamentary activities in over 25 countries) can provide a key tool for the understanding of specific crises such as the COVID-19 global pandemic as well as more general social and political trends across countries and languages.

Keywords: valence, emotion, politics, positivity, parliament, psycholinguistics, COVID-19, hansard corpus

\section{INTRODUCTION}

Canada, like many other countries around the world, has a parliamentary system of government that has developed from the British (or Westminister) style of government. Thus, in the Canadian system, bills that are introduced in the House of Commons must be approved by the Senate and are signed into law after approval by the Governor General of Canada. This process is almost exclusively carried out through verbal means.

The goal of our study was to examine this linguistic activity and, in particular, to investigate how the emotional characteristics of the words used by Canadian Members of Parliament reflect the political realities within parliament and the surrounding social context. 
Our study addresses the very recent past (2006-2021). At the same time, however, it taps into linguistic patterns that are likely centuries old. The English Parliament had its linguistic and political roots in the Magna Carta of 1215. Over the 800 years of its development, it has changed considerably in its purpose, role, composition, and procedures. Yet, parliament remains fundamentally an institution of speech, carrying within it the Old French word parle-ment.

It is very likely that Members of Parliament have always, on average, been extremely adept language users. Then, as now, their positions require that they be attuned to the power of words to affect and reflect people's cognitive and emotional states. Thus, politicians speaking in parliament must choose their words, for they are typically hopeful that those words will have immediate and perhaps long-term consequences. More recently, they also know that their words will be transcribed, translated, and kept as a publicly available document. This publicly available document is called 'The Hansard'.

\section{What Word Choice Can Reveal}

A core characteristic of our analysis is its focus on individual words and their characteristics. As we describe more fully below, our core psycholinguistic resource was the database of word ratings reported by Warriner et al. (2013). This database contains data from 1,827 participants who rated the emotional valence of 13,915 English words in an online rating study. A key feature of the methodology was that each word was rated in isolation so that participants had to judge, for example, how positive the word 'vacation' is or how positive the word 'crisis' is. The methodology resulted in each word being rated by approximately 18 participants. We reasoned that such valence ratings constitute estimates of how positive a word is, all other things being equal. Such positivity estimates might then play a role in the word choices made by politicians in a parliament setting. For example, Members of Parliament whose party is in power might be less likely to use words such as 'chaos', 'corruption', and 'crisis', whereas these are exactly the kinds of word choices that Members of the opposition party might find quite attractive to use. By linking such word choices to specific events, political parties and political roles, we set out to identify markers of political culture with an existing psycholinguistic resource.

Indeed, in the fifteen years of parliamentary speech that we have investigated (from the opening of the 39th parliament on April 3, 2006 to the 96th meeting of the 43rd parliament held on May 6, 2021), there have been dramatic shifts in Canadian political dynamics. The New Democratic Party rose to the role of the opposition party for the first time in its history, the Green Party secured their first House seats, the Bloc Quebecois saw massive shifts in representation, losing and regaining its Third Party status, and both minority and majority governments were formed by the Conservative Party of Canada and the Liberal Party of Canada. These changes have made it possible for us to examine how the patterns of word positivity associated with particular political parties may change as their political roles in parliament change. The 15-years span that we selected allowed us to investigate the recent eventful years in-depth and to contextualize that investigation with data from the years that preceded them. Limiting the span to 15 years allowed us to be confident that the valence ratings provided by Warriner et al. (2013) would be current.

Importantly, our span of analysis includes the time since the onset of the COVID-19 pandemic. During this period, the entire Canadian political system has been subject to a sudden stress test imposed by the greatest public global health crisis in over a century. It was our expectation that the cooperative rallying of Members of Parliament that would be required to meet the demands of this crisis would be reflected in greater positivity of the words used across political parties. If these expectations are correct, it would constitute evidence that an independently obtained psycholinguistic measure of the affective properties of words are reflected in the speech choices of Members of Parliament. These, in turn, may reflect their conscious and perhaps unconscious responses to public anxiety and the means by which they can adjust the 'political temperature' in parliament.

There is psycholinguistic evidence suggesting that such conscious or unconscious word choices could have such effects. Comprehension of the meaning of a word that a person encounters can occur in under a fifth of a second (Davis et al., 2019). Moreover, that comprehension is both automatic and obligatory (Libben, 2020). This has substantial consequences for the understanding of language processing within the political realm. In short, it suggests that a language user who is able to understand the words of a language is not able to block that understanding. There is also a growing body of evidence suggesting that this automaticity could extend to emotional responses to words. Using a lexical decision task, Kousta et al. (2009) found that words with more extreme valences (i.e., either more positive or more negative) were processed more quickly than words with less extreme valences. Whether or not there is a bias towards the processing of positive or negative words has not yet been determined (see also Kuperman et al., 2014) and there are likely to be new developments forthcoming (see van Berkum, 2018).

In a subsequent study, Kousta et al. (2011) found that emotional properties play a particularly strong role in the representation of abstract words. These are the kinds of words that would be expected to appear more commonly in formal settings, including parliamentary debate.

The automaticity of the emotional dimension of words was evident in the results of Harp et al. (2020) who found that words that are ambiguous in their valence (i.e., can be interpreted differentially as either positive or negative) are processed more slowly than words that were unambiguously either positive or negative. Processing times and judgments were measured through a valence bias task in which a participant sees a word in the center of a computer screen and must judge it as positive or negative by pressing one of two keys on the keyboard. The valence of words has been shown to affect lexical decision latencies (Crossfield and Damian, 2021) as well as ERP correlates in a lexical decision task (Imbir et al., 2016).

The findings above support a view of lexical processing that is automatic and obligatory and, within which, the emotional 
properties of words play an important role. Based on this view, it is possible that the valence of individual words becomes automatically activated and cannot be entirely inhibited by surrounding context. We expect that in the House of Commons, where Members are deliberate in their choice of language and highly sensitive to the emotions they evoke, that an analysis of individual word valence would provide valuable insight.

\section{Using the Hansard to Study the Language of Parliament}

The research we report is made possible by the existence and public availability of The Hansard Database. This has allowed us to link emotional valence measures to over 35 million of the 91 million words spoken in the Canadian House of Commons between May 2006 and April 2021.

The Hansard originated as the name given to the records of parliamentary debates in the United Kingdom. It is named after Thomas Curson Hansard (1776-1833), the first official printer to the Parliament at Westminster. The parliament of the United Kingdom describes The Hansard as a 'substantially verbatim' report of what is said in Parliament. It notes that the words spoken by members are recorded, but that postediting is conducted to remove repetitions and obvious mistakes (UK Parliament, 2021).

The Hansard system is currently used by over 25 countries, including Canada. The Canadian Hansard, which dates back to 1880, contains the records of debates in the House of Commons in both English and French. It thus represents one of the largest French-English bilingual texts available. As a result, The Hansard has been a key resource for the development and testing of English-French machine translation systems (e.g., Fraser and Marcu, 2007; Kurokawa et al., 2009).

The Hansard has played an extremely important role in ensuring that the content of parliamentary debate is available to the public. It has also provided a rich resource for political and linguistic scholarship. For example, Ryan et al. (2009) used the Hansard record to analyze the dynamics of the gun control debate in the Canadian House of Commons. Their report included a lexical analysis component, beginning with a frequency analysis, over the years 1995-2008 of the number of words spoken by each party and, in particular, the frequency of speech by particular MPs within each party on the issue of gun control. Focusing on the linguistic properties of The Hansard, Carpuat (2014) conducted an analysis of Hansard transcripts of Canada's House of Commons and its committees from 2001 to 2009 in order to detect patterns of English-French language mixing and code-switching within a turn taken by parliamentary speakers.

A very relevant study of the use of The Hansard in the investigation of emotion in parliamentary debates was reported by Rheault et al. (2016). They analyzed emotion in British parliamentary speech using automated textual analysis. They found that, in the period from 1909 to 2013, parliamentary speech increased in positivity and, overall, the speech of politicians in power was more positive than that of those in the opposition party. They also linked emotional polarity in the
British parliament to the country's history of labour disputes and found that emotional polarity in parliament can be predicted by the state of the national economy.

The design of our study enabled us to determine whether patterns such as the greater positivity of the party in power reported by Rheault et al. (2016) also hold in the Canadian context. As Rheault et al. (2016) note, the finding itself is not surprising. In the United Kingdom's Westminister system, which is also used in Canada, it is the duty of the opposition to question the party in power and to challenge its proposals and decisions. It is thus expected that they would use less positive words with which to do so. In our analysis, however, we sought to go beyond a simple test of this prediction. First, we sought to establish overall patterns of lexical positivity by Party and then to assess how those patterns changed from the 2006 election over the changes resulting from the subsequent elections in 2008, 2011, 2015, and 2016. We also sought to determine the extent to which patterns of positivity across parties were affected by the extent to which the party in power held a majority in the House of Commons or, as a minority government, required support from at least one other party in order to be assured of a majority vote on an issue (and, more crucially, the ability to survive a non-confidence vote that would trigger an election). Finally, we distinguished between the official opposition in the House of Commons and the other parties that did not form the government. In the Rheault et al. (2016) study, the 'opposition; included all Members of Parliament who did not belong to the party currently forming the government.

As we have noted above, the span of time that we investigated included the period from the onset of the global COVID-19 pandemic. We thus considered it to be important to document the language changes in Parliament that are linked to the onset of the pandemic by comparing the valence of words before the pandemic to those during the pandemic. We augmented this analysis by including, in our dataset, the monthly COVID-19 case counts in Canada since February 2020. By linking those to our valence analysis, we could create a fine-grained assessment of the extent to which the often turbulent events in the social context are mirrored in the emotional characteristics of the words used in parliament at that same time period.

\section{METHODS}

\section{The Hansard Text Resource}

We constructed our corpus from the Hansard texts gathered from the Canadian House of Commons website (https://www. ourcommons.ca/). The reports are prepared and published by the Hansard Association of Canada (HAC), which is a nonpartisan organization responsible for producing official reports of all legislative debates in Canada. As we have noted above, The Hansard documents are not verbatim transcriptions, though they have been described as 'substantially verbatim' by those who produce them (Caruso et al., 2015). Transcriptions are minimally edited according to strict style guidelines set out by the HAC and under the scrutiny of House Members. These guidelines allow for the correction of inconsequential, or non-political, speech errors 
TABLE 1 | An excerpt taken from the Edited Hansard No. 84 for the 2nd Session of the 43rd Parliament held on April 20 th' 2021.

\begin{tabular}{|c|c|}
\hline Speaker & Speech \\
\hline \multicolumn{2}{|l|}{ Justin Trudeau } \\
\hline $\begin{array}{l}\text { Prime Minister } \\
\text { Liberal Party of Canada }\end{array}$ & $\begin{array}{l}\text { Mr. Speaker, it is important in this House that we be grounded in facts. Our plan is working, and we are getting more vaccines } \\
\text { than anticipated. We have now delivered over } 13.3 \text { million doses to provinces and territories, with more than } 10 \text { million doses } \\
\text { of vaccine already administered. Thanks to the tireless work of officials to accelerate vaccine deliveries, we are now in the top } \\
\text { three of G7 and G20 countries. }\end{array}$ \\
\hline $\begin{array}{l}\text { Erin O'Toole } \\
\text { Leader of the Opposition } \\
\text { Conservative Party of Canada }\end{array}$ & $\begin{array}{l}\text { Mr. Speaker, his plan is working. Moderna was delayed and doses were reduced. AstraZeneca was delayed and doses } \\
\text { were reduced. This morning, production of the J\&J vaccine has been suspended at the main facility. Supply shortages will } \\
\text { only get worse as more Canadians become eligible for shots. }\end{array}$ \\
\hline
\end{tabular}

(i.e., those not remarked upon by other members) and the removal of false starts, repetitions, redundancies and heckles (Caruso et al., 2015). Corrections can be made to the Hansard with the approval of the House and only if the correction is deemed politically important (Hansard Association of Canada, 2021). We considered these alterations to be largely inconsequential to our analysis, which focus primarily on content words within a given speaking turn and not the features of spoken language production likely to be edited out.

The HAC produces two documents for each meeting of the House: one English and one French. The most substantial alteration made to the Hansard is translation. Roughly $23 \%$ of the speech produced in the House is French, with the remaining 77\% being English. All French speech is translated into English by a team of translators at Public Services and Procurement Canada's Translation Bureau and published in the Hansard. These translations aim to capture the meaning of what is said and are therefore not literal. In our analysis, we were careful to distinguish between words transcribed in English and those translated from French.

Table 1 shows a sample of the Canadian Hansard transcript. As can be seen in Table 1, the Hansard transcript can be considered as a series of 'turns'. In each turn, the Member speaking is identified and the content of the speech is recorded.

The Hansard analysis that we report examined the speech of all five of the currently 'represented' Canadian political parties, i.e., the Bloc Québécois $(\mathrm{BQ})$, the Conservative Party of Canada (CPC), the Green Party (GP), the Liberal Party of Canada (Lib), and the New Democratic Party (NDP). Speeches made by these parties accounted for an overwhelming majority of our data set (99.97\%) compared to those made by members of other political or social groups $(0.03 \%)$. Given the paucity of available data, we would not have been able to confidently extrapolate patterns of language usage regarding members of other groups.

\section{The Warriner et al. Database of Word Ratings}

The development of the Warriner et al. (2013) database is part of a wave of development that has transformed psycholinguistic research over the past decade (Keuleers et al., 2020). This wave has resulted in the creation of large databases that link individual words to specific characteristics both within and across languages. The
TABLE 2 | Four example entries taken from the Warriner et al. database exemplifying the extremes of positive and negative emotional valence.

\begin{tabular}{lcc} 
& Mean valence & Standard deviation \\
\hline Vacation & 8.53 & 0.77 \\
Cure & 7.81 & 1.33 \\
\hline Crisis & 2.05 & 1.08 \\
Virus & 1.71 & 0.78
\end{tabular}

Words that were rated as more positive have high values. Words that were rated as more negative have low values.

Warriner et al. (2013) database is the result of a study that sought to advance the understanding of the emotional dimensions of words by asking native speakers of English to rate English words in terms of valence (positivity vs negativity), dominance (the degree of control conveyed), and arousal (the intensity of the emotion conveyed). Importantly, the authors only selected the highest-frequency words known by $70 \%$ or more of the participants [as determined in Kuperman et al. (2014)]. This strategy was employed because affective ratings are less valid/useful for words that are not known to most participants.

Overall, 13,915 English words were rated in an online experiment conducted using the Amazon Mechanical Turk platform. A total of 1,827 participants contributed to the creation of the database and each word received approximately 18 ratings on each of the three affective dimensions.

In our analysis, we have focused on the dimension of valence, which emerged in the Warriner et al. (2013) study as the most reliable of the emotional dimensions. An example of the valence data made available by this database is presented in Table 2 .

\section{Constructing the Corpus Used in the Present Study}

The corpus for the present study was constructed in RStudio (RStudio Team, 2020) from 1,675 Hansard documents downloaded in Extensible Markup Language (xml) format. The corpus was first divided into individual speaking turns (n $=427,849$ ), from which procedural directions by The Speaker, Deputy Speaker, and Assistant Deputy Speaker were removed and the speaking turns taken by members of represented parties selected $(\mathrm{n}=389,841)$. Using the 'tidyverse' set of $\mathrm{R}$ packages (Wickham et al., 2019) and tidytext (Silge and Robinson, 2016), 
TABLE 3 | Rate of retention after lemmatized tokens without a rating in the Warriner et al. database were removed from the corpus.

\begin{tabular}{|c|c|c|c|}
\hline Political party & Tokens available & Tokens included & Retention rate \\
\hline Bloc Québécois (BQ) & $7,008,457$ & 2,695,222 & $38.5 \%$ \\
\hline Conservative (CPC) & $32,330,273$ & $12,726,099$ & $39.4 \%$ \\
\hline Green Party (GP) & $1,068,340$ & 405,973 & $38.0 \%$ \\
\hline Liberal Party (Lib) & $25,561,872$ & $10,013,830$ & $39.2 \%$ \\
\hline New Dem. Party (NDP) & $25,744,447$ & $9,923,678$ & $38.5 \%$ \\
\hline Total & $91,713,389$ & $35,764,802$ & $39.0 \%$ \\
\hline
\end{tabular}

A breakdown is provided by political party.

TABLE 4 | A breakdown of the process of obtaining valence ratings for content word tokens in each speaking turn and calculating the average valence of those tokens.

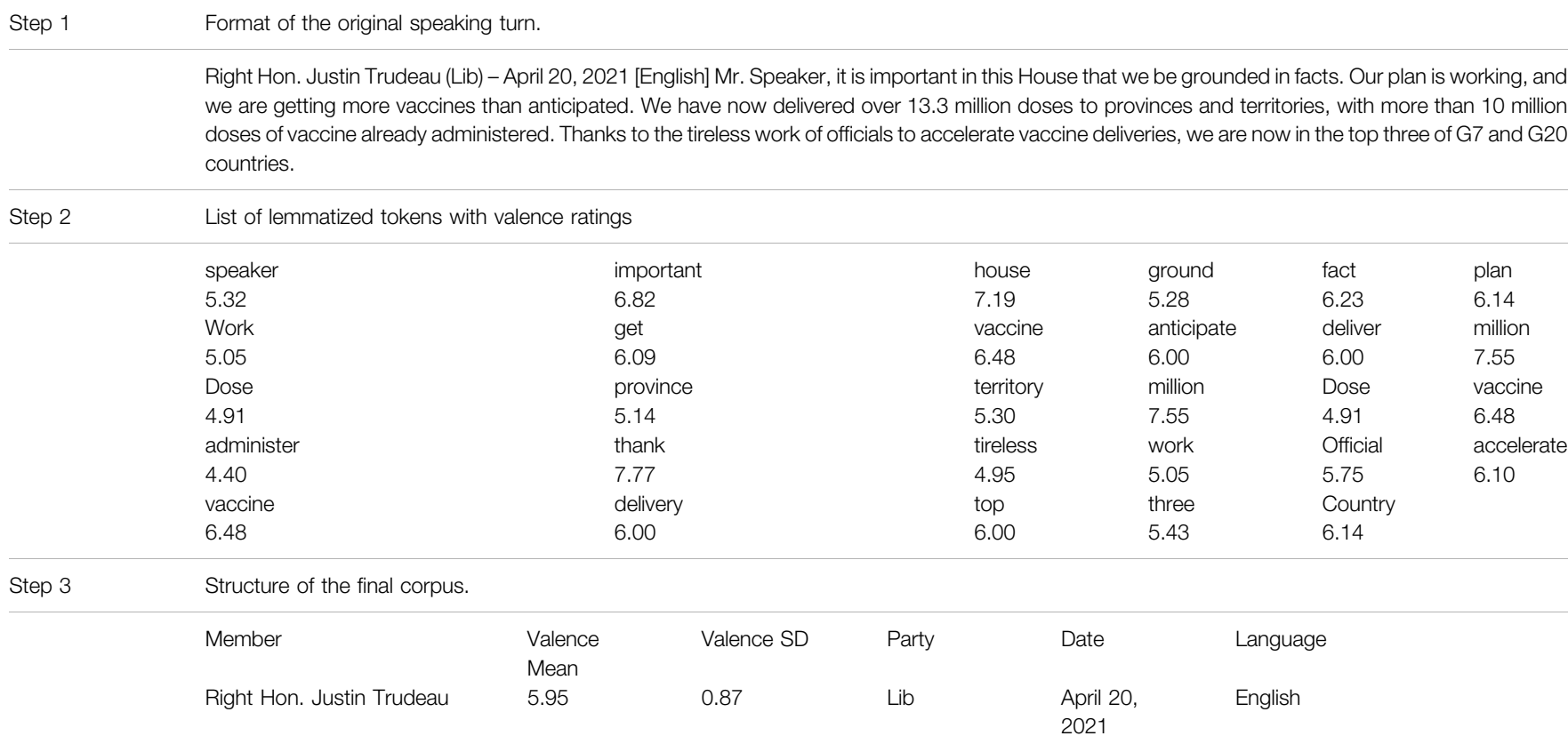

each speaking turn was split into individual tokens $(\mathrm{n}=$ 91,713,389). Each token was then lemmatized using a database of English inflected tokens and their corresponding root lemmas (Mechura, 2016). Grammatical function words (or 'stop words') were identified using a canonical English list in the text-mining package 'tm' (Feinerer et al., 2008) and removed. Valence ratings for each remaining token were then matched from the Warriner et al. database and tokens without ratings were dropped. This left $39 \%$ of the original corpus, or $35,764,802$ non-grammatical content word tokens with valence ratings. To ensure that this process did not unfairly bias the inclusion of lemmas from any one political party, retention rates by party were calculated (see Table 3). In the final step, all remaining tokens were regrouped into their original speaking turns and the mean and standard deviation of valence was calculated for each. A breakdown of this process for a single speaking turn is shown in Table 4 (Parliament of Canada, 2021).
Our final corpus consisted of 389,841 speaking turns (as in Table 4, Part 3) taken during debates in the Canadian House of Commons. Each speaking turn was tagged by language, date, and the member speaking. In cases in which members switched between English and French during a speaking turn, that turn was labelled 'bilingual'. In all other cases, language was either 'English' or 'French'. The gender and political affiliation of each member were added. Each speaking turn was tagged with information regarding the political party in power, the minority or majority status of the government, and the party assuming the role of the opposition at the time the speech was given. Speaking turns were also tagged for whether they occurred before or after the onset of the COVID-19 pandemic (March 2020), when the first travel-related cases were reported in Canada. The final corpus contained the approximate valence of each speaking turn tagged by the political and societal conditions that we wished to investigate. 


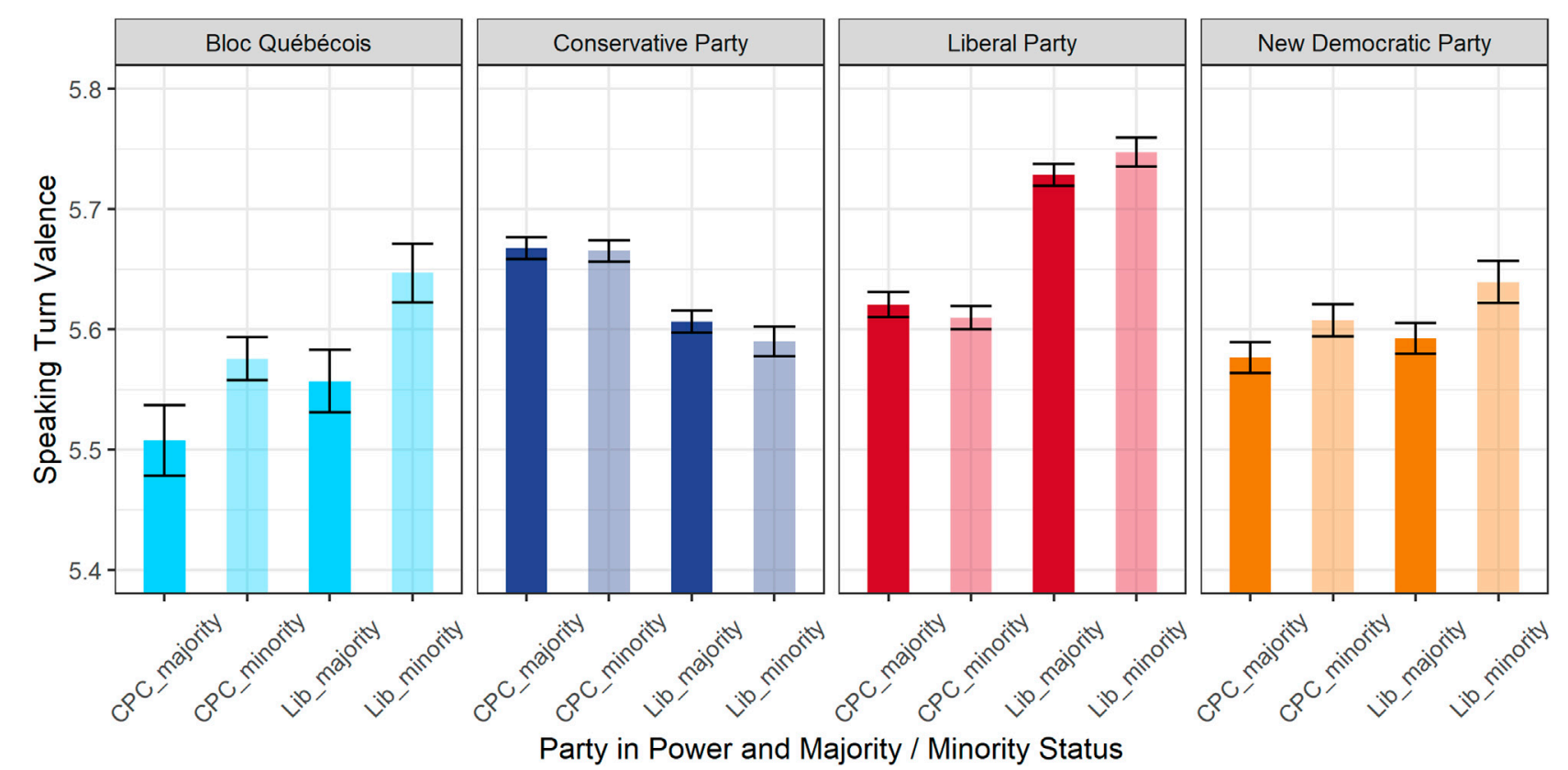

FIGURE 1 | Speaking turn valence for the BQ, CPC, Lib, and NDP depending on the party in power and the majority or minority status of the government (i.e., whether the party in power holds more than $50 \%$ of the seats in Parliament), based on the estimates of a linear mixed-effects regression model (see Supplementary Table S1 for model summary). Error bars represent 95\% confidence intervals. Majority government status is indicated by darker colored bars and minority government status by lighter colored bars.

\section{RESULTS}

\section{Statistical Modeling}

Linear mixed-effects regression modeling was used to determine whether political factors influence the affective characteristics of words used by Members of The House of Commons. The strength of this statistical method is that it allowed us to control for some random variation across our predictor variables. For instance, we were interested in whether belonging to the party in power might influence one's language use. However, we recognized that variation within a party is likely greater than variation between parties due to many idiosyncratic factors. Mixed effects regression allowed us to build that assumption into our model by including 'Member' as a random factor. 'House Session' was similarly included to account for session-specific features such as debate-topic, proximity to upcoming elections, and general atmosphere, which could presumably influence the valence of speaking turns on that day.

Our models were constructed using forward stepwise variable selection (Levshina, 2015). This process selects, from a set of control variables, only those that improve model performance. The variable set included: a) the floor language during a speech, b) the gender of the Member speaking, and c) whether the Prime Minister attended the debate. In each of the models reported below, the control variables that significantly improved model performance were 'floor language' and 'Prime Minister attendance'. No statistically significant differences were observed for 'Member gender' in any of our models.

\section{Lost or Gained in Translation?}

A substantial number of the speeches included in our analysis were delivered in French $(\mathrm{n}=95,306 ; 24.4 \%)$ or in both English and French $(\mathrm{n}=13,948 ; 3.6 \%)$. In these cases, the words we analyzed were not those produced by the speaking member. This opened the possibility that our data could have been affected by a French word and its corresponding English translation sharing the same referent but not precisely the same emotional properties. To examine this possibility, we created a linear mixed effect regression model with mean speech valence as the dependent variable, floor language (including speeches delivered bilingually) as a fixed factor, and the Member speaking as a random factor. The results suggested that, compared to speech delivered in English, those delivered in French included less positive language (estimate $=-0.015, \mathrm{t}=-8.15, p=<0.001$ ) and those delivered bilingually included more positive language (estimate $=$ $0.055, \mathrm{t}=21.06, p=<0.001)$. A summary of this model is provided in Supplementary Table S1. To account for this effect of floor language on speech valence, we opted to include it as a covariate in all regression models reported below.

\section{The Power of Positivity}

The nature of the parliamentary system seems to motivate governing parties to exude more positivity compared to those parties vying for power. Our data provided an opportunity to evaluate these expectations. We fitted a linear mixed-effects regression model for the mean valence of members' speeches. We included the political party-in-power and the minority/ 
majority status of their government (as a single predictor variable with four-levels: CPC-majority, CPC-minority, Lib-majority, Lib-minority). We also included an interaction with political party to determine how this dynamic influenced the language valence behavior of members of each party. The pattern of effects is shown in Figure 1. A summary of the model output, including statistics for both fixed and random effects is provided in Supplementary Table S1.

The results of this analysis show that political power does influence the valence of language used by House Members. According to the model estimates, when the Lib were in power, their Members used significantly more positive language (estimate $=0.092, \mathrm{t}=21.35, p=<0.001$ ) and Members of the CPC used significantly less positive language (estimate $=-0.077, \mathrm{t}=-21.44, p=<0.001$ ) compared to times when they held power. These differences in positivity were significantly greater compared to both the $\mathrm{BQ}$ (estimate = 0.033, $\mathrm{t}=2.003, p=<0.001$ ) and the NDP (which was the baseline comparison group in this analysis). This suggests that the effect of political power is not an artifact of the times during which parties held power, but rather an effect of the political dynamics themselves.

During minority governments, Members of the House tended to use more positive language overall (estimate $=0.031, \mathrm{t}=7.152$, $p=<0.001$ ), which may reflect the greater degree of cooperation 'across the aisle' that must happen to pass legislation. In such times, it was the BQ (estimate $=0.037, \mathrm{t}=2.659, p=<0.001$ ) and NDP (baseline) that tended to use more positive language compared to the CPC (estimate $=-0.033, \mathrm{t}=-8.792, p=<$ 0.001 ) and Lib (estimate $=-0.042, \mathrm{t}=-8.961, p=<0.001$ ). In the case of the CPC, this seemed to depend largely on which party was in power. When the Lib held power with a minority, CPC Members tended to use less positive language (estimate $=-0.03, \mathrm{t}$ $=-3.98, p=<0.001)$. However, the opposite was observed when it was the CPC that held power with a minority. The Lib Members show a similar, yet statistically insignificant, tendency to be more positive while in power with a minority (estimate $=0.014, \mathrm{t}=$ 1.763, $p=0.08$ ). Taken together these findings suggest that political power goes hand in hand with positive language use, whether that power is derived from your own party's strength, i.e., being in power, or other party's relative lack of power, i.e., a minority government. In a series of post-hoc analyses, we found that this relationship was not only true for more macro shifts in political power dynamics but also for the specific number of seats held by a party.

Visually inspecting the pattern of speaking turn valence for the BQ in Figure 1 revealed an interesting relationship. Valence seemed to closely align with the representation of the BQ in the House. During the 41st Parliament, when the CPC held a majority government, the BQ held the fewest number of seats since its founding. We re-ran the above model for speaking turns taken by Members of the BQ only and confirmed that it was during this parliament that their speeches were least positive $(\mathrm{t}=$ -4.693, $p=<0.001)$.

A follow-up analysis was conducted to determine if this finding could be generalized to other political parties. Another model was constructed that included the same control variables used above with 'number of seats' as the key independent variable. The predictors 'party-in-power', 'minority/majority government', and 'party' were not included. Results confirmed our hypothesis that having more representatives in the House significantly increased the positivity of language used by those Members (estimate $=0.005, \mathrm{t}=33.06, p=<0.001$ ). This suggests that the link between positive language use and power is sensitive to more fine grain shifts in political representation than we had originally expected.

\section{The Devil's Advocate}

There is a potentially confounding factor when it comes to the number of seats won by a party and the language use of its members: The party with the second largest representation in the House acts as the opposition, a role that involves actively critiquing and challenging the proposed policies of the governing party. In this analysis, we investigated whether speaking turn valence was impacted when a Member belonged to the official opposition party. We used the variable 'number of seats' held by a party (introduced in the above analysis) as a control variable for political power as well as all of the same control variables used in previous models. Only parties that had acted as the official opposition since 2006 were included in this analysis. The pattern of effects is shown in Figure 2.

According to our results, being a Member of the opposition was associated with significantly less positive language use (estimate = $-0.039, \mathrm{t}=-10.71, p=<0.001)$. This is unsurprising given the opposition's role to question and critique the actions of the governing party, as noted by Rheault et al. (2016). The only notable difference across the three parties was that the Lib tended to use more positive language overall (estimate $=0.044, \mathrm{t}=7.899, p=$ $<0.001$ ), yet showed the greatest drop in positive language use when acting as the opposition (estimate $=-0.026, \mathrm{t}=-4.949, p=<0.001$ ). No significant differences between the CPC and NDP were observed in this regard. These results complicate the relationship between power and positive language use, showing that the role that a party plays in House debates also influences the valence of language that Members tend to use.

\section{Coming Together in a Crisis}

Our final analysis concerned the language choices made by Members during the on-going (at the time of writing) COVID-19 pandemic. We probed whether a global event could influence the valence of speeches made in the House. We, therefore, created a model of speaking turn valence for speeches made before and after the onset of the pandemic in Canada (March 2020). The same set of control variables from previous models were used again in this model. The pattern of effects is shown in Figure 3.

Our results indicated that House Members tended to use more positive language after the onset of the pandemic (estimate $=0.05$, $\mathrm{t}=5.26, p=<0.001)$. This is true for all political parties excluding the CPC (estimate $=-0.077, \mathrm{t}=-8.492, p=<0.001$ ). However, it is important to note that the CPC has functioned as the official opposition party for the duration of the pandemic, a role which, based on our previous analysis, is associated with more negative language use, irrespective of which party is taking on the role. 


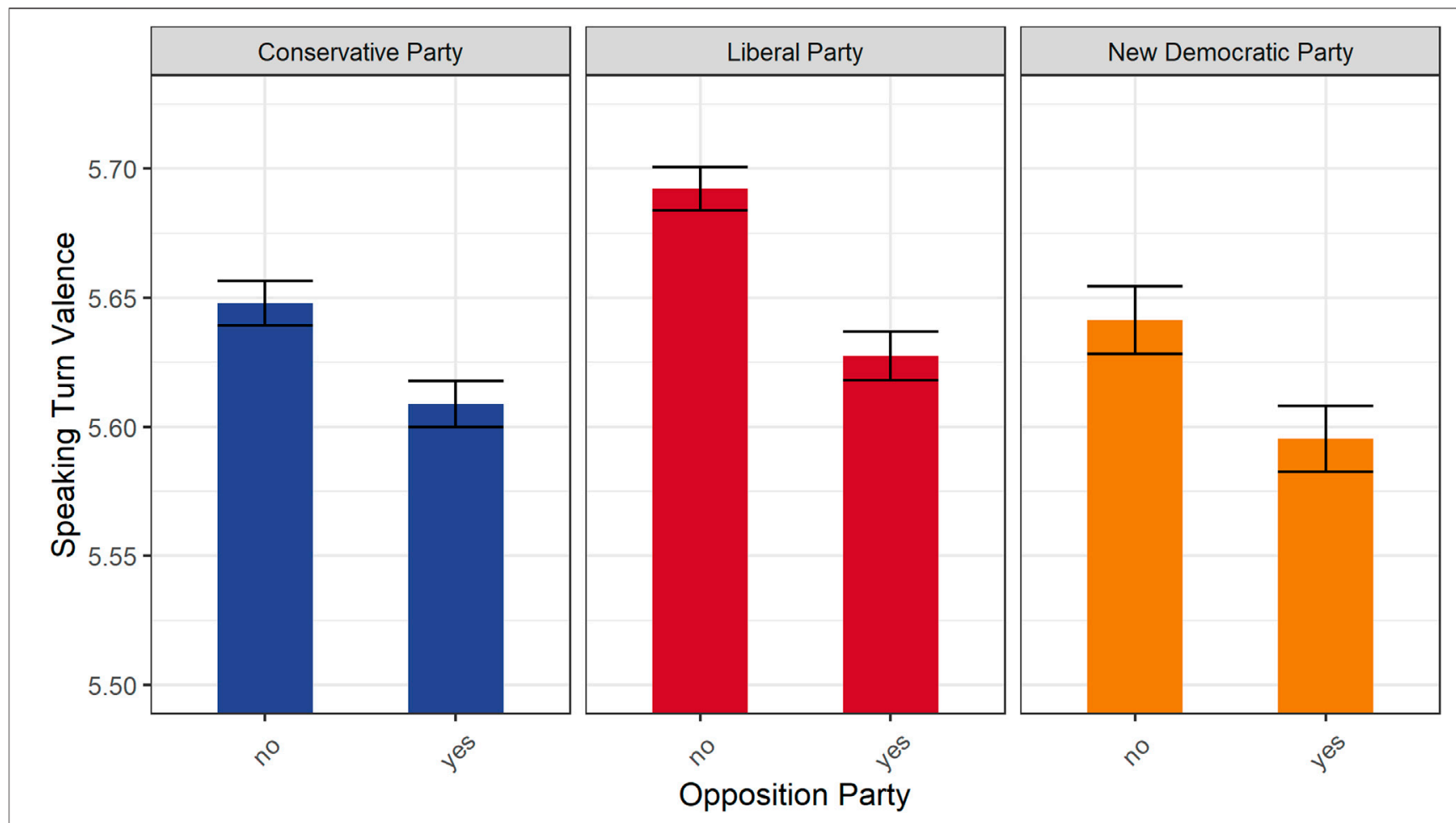

FIGURE 2 | Speaking turn valence for the CPC, Lib, and NDP. For each party, two bars are shown. This first shows average speaking turn valence when the party was not the official opposition. The second shows valence when the party did have the role of official opposition party. Values are based on the estimates of a linear mixed-effects regression model (see Supplementary Table $\mathbf{S 2}$ for model summary). Error bars represent 95\% confidence intervals.
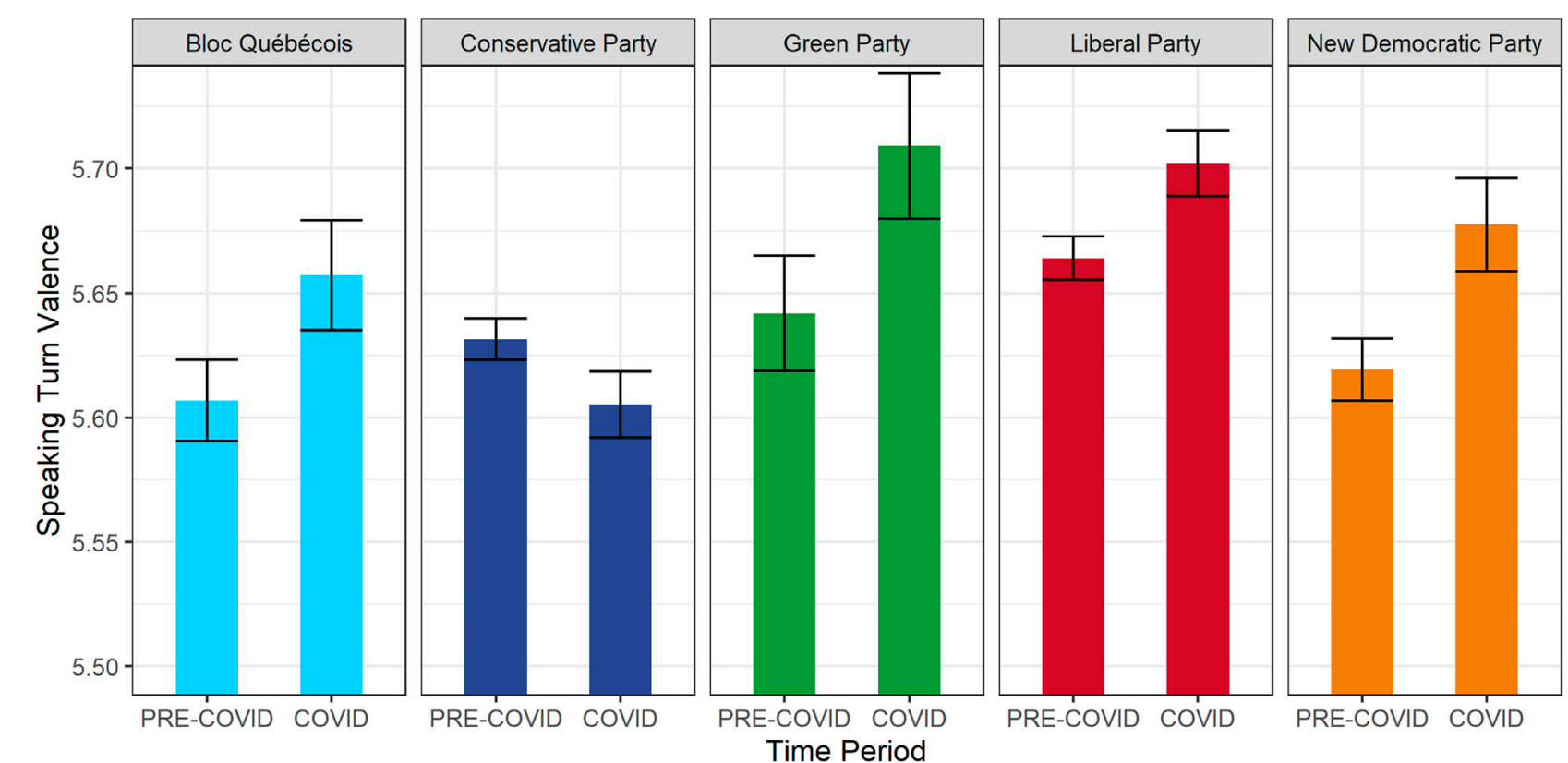

FIGURE 3 | Speaking turn valence for all represented Canadian political parties before and after the onset of the COVID-19 pandemic, based on the estimates of a linear mixed-effects regression model (see Supplementary Table S3 for a summary). 


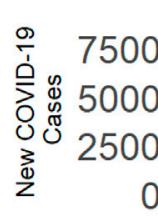

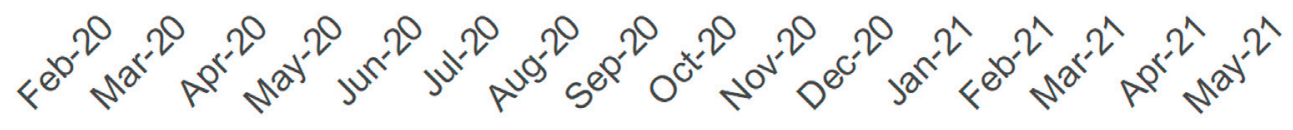
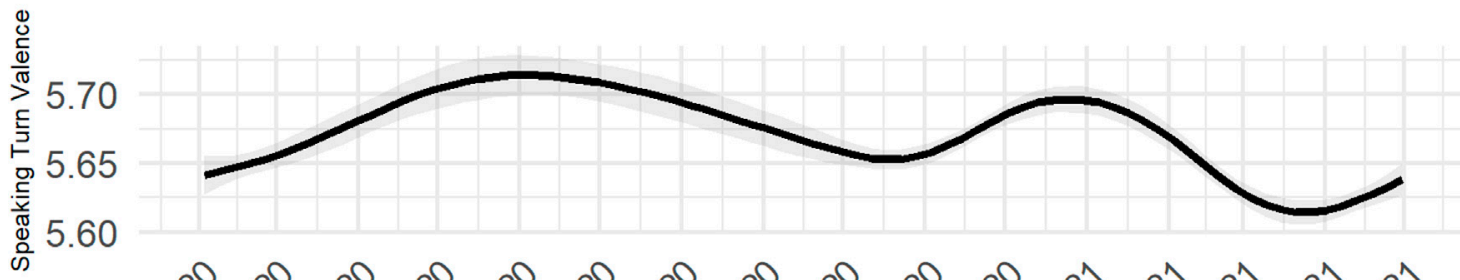

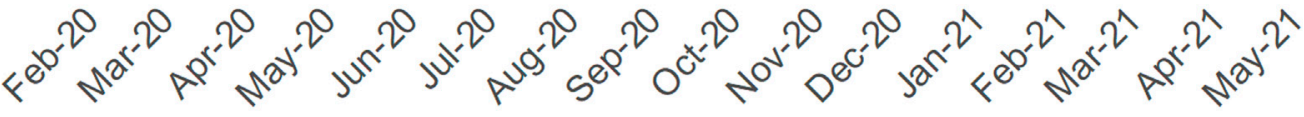

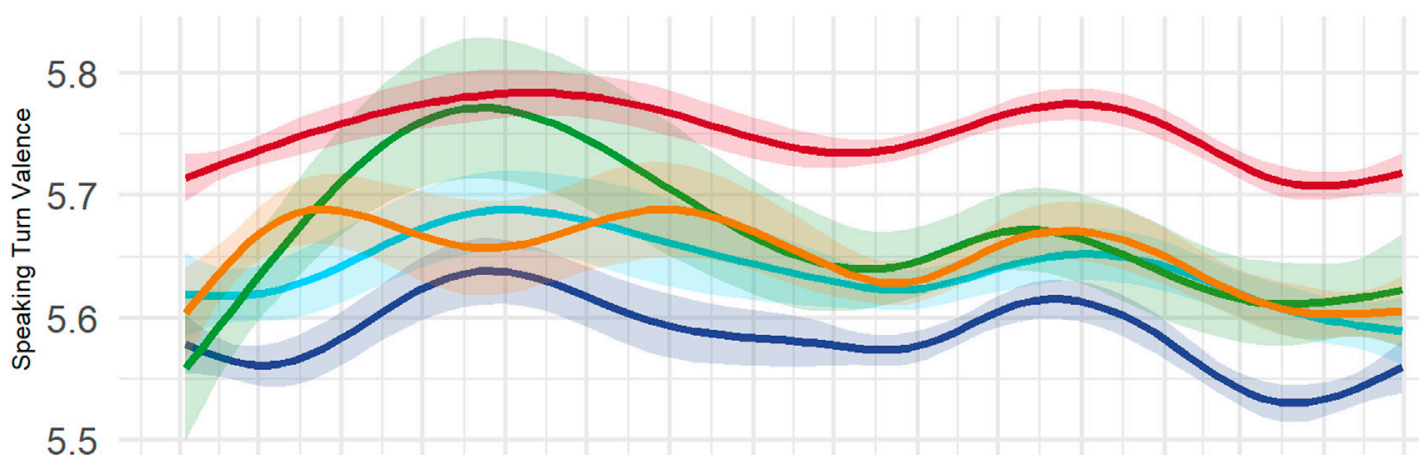

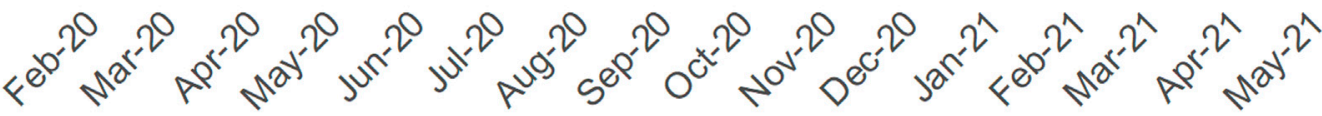
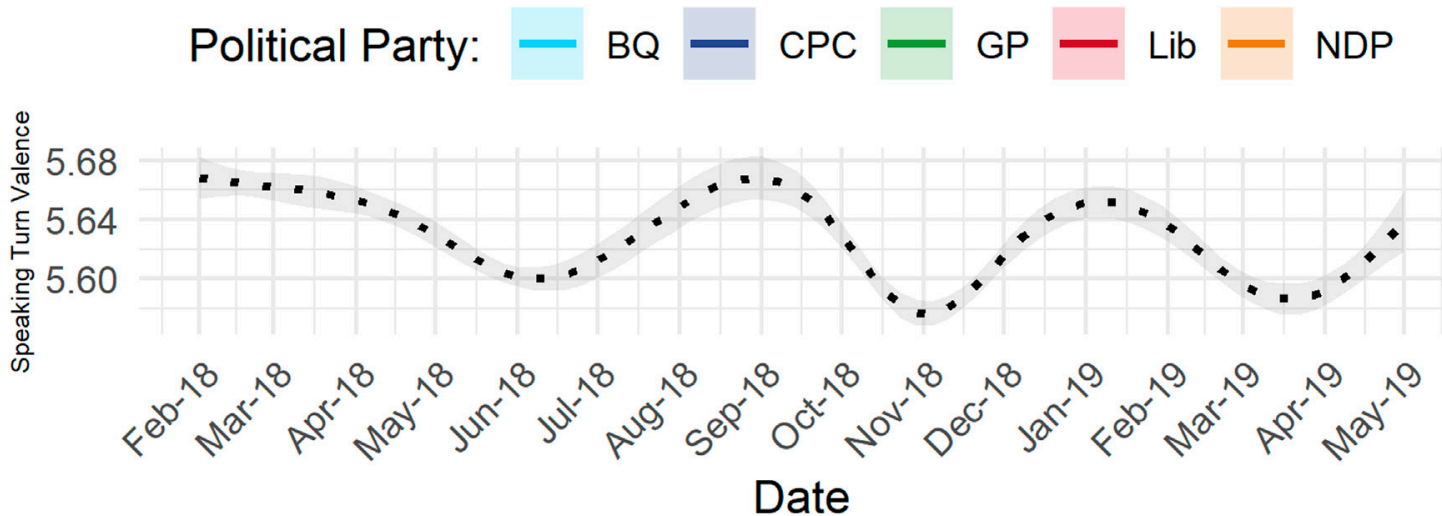

FIGURE 4 | The top three plots display (Top) the number of new COVID-19 cases reported in Canada, (Second from the top) speaking turn valence, and (Third from the top) speaking turn valence for each represented Canadian political party over the course of the pandemic by month. Speaking turn valence estimates are based on a generalized additive regression model with date as an independent ordinal variable. Shadowed areas above and below each line represent upper and lower 95\% confidence intervals. The plot with the dotted line (Bottom) shows a comparison pattern for the same months in 2018-2019 (i.e., the comparable pre-COVID-19 pattern). 
To what extent does this finding support the notion that Members are coming together in times of crisis? Using generalized additive regression, which allows for the plotting of non-linear relationships, we plotted the changes in the speaking turn valence made by Members of each party and Members overall over the course of the pandemic. Along the same $x$-axis, we also plotted the number of new COVID-19 cases reported in Canada for comparison.

A visual inspection of the rises and falls in speaking turn valence over the course of the pandemic (shown in Figure 4) suggests that they closely patterned with the number of new COVID cases reported. Another post-hoc analysis was conducted to investigate this possibility. A linear mixedeffect regression model was fitted for the relationship between case count and valence across the three waves of COVID-19. The model included 'party', 'language', and 'Prime Minister present' as control variables, 'Member' as a random factor, and 'number of new COVID-19 cases' (on a log scale) and COVID-19 wave (i.e., first, second or third) as the main variables of interest. The boundaries of each wave were determined by their first mention in the House debates $($ first $=2020-02-21$, second $=2020-09-25$, third $=2021-03-23)$.

Model output (see Supplementary Table S4) indicated two significant patterns of positive language use. The first was that less positive language was used during the second wave (estimate $=-0.034, \mathrm{t}=-5.486, p=<0.001$ ) and third wave (estimate $=-0.073, \mathrm{t}=-9.463, p=<0.001$ ) compared to the first wave. This finding may reflect the sense of exhaustion and frustration that accompanied the latter stages of the pandemic. The second, more surprising finding, was that significantly more positive language was used on days when higher numbers of COVID-19 cases were reported (estimate $=0.09, \mathrm{~F}=3.328$, $p=<0.001)$. This finding may indicate that House Members employed more positive language as a means of coming together in times of crisis. It may also be linked to Members' expectations. Fewer new case counts were observed at the onset of each wave, where future case counts were expected to rise. Conversely, the largest case counts were observed near the peaks, where case counts were expected to soon fall. Members tended to use more positive language leading up to the approval of the first COVID-19 vaccine by Canada Public Health. To the extent that these findings reflect deliberate language decisions, they suggest that House Members use positive language in a crisis when their expectations for the future are brighter. To the extent that they reflect unconscious language behavior, our findings suggest that language use is sensitive to the broader societal context in which it occurs.

\section{DISCUSSION}

In this paper, we investigated the emotional properties of language used in the Canadian House of Commons debates over the past 15 years. This was made possible by the Canadian Hansard, which provides digital transcriptions and translations of all House debates. Using these documents, we isolated every individual word spoken during House Sessions from 2006 to May 6, 2021, and approximated the emotional properties of those words using normative valence ratings taken from the Warriner et al. (2013) database.
Our findings show a strong relationship between the use of positive language and political power. This relationship can be observed using coarse-grained measures, i.e., which party is in power and the majority or minority status of the government, and surprisingly, more fine-grained measures, such as the relative number of seats held by a given party at a given time. This suggests that, at an individual level, the language choices made by House Members are sensitive to the power dynamics among parties, either consciously, unconsciously or both.

This relationship is of course complicated by the roles that each party plays in Parliament. Our results clearly illustrate that Members of opposition parties tend to use less positive language. However, this is also likely to play out at the individual level, as Members within parties assume various stances and roles which require the deployment of more positive or negative language.

Our findings support the view that the relationship between positivity and power can be captured through the analysis of individual word properties. This, in turn is consistent with existing evidence that, because lexical processing is automatic and obligatory, language users cannot help but process the emotional properties of words. Thus, it may simply be the case that a person's reactions to words are so immediate and so automatic that they cannot be fully inhibited by the context in which they appear.

The sensitivity of this approach to the analysis of political language was particularly evident in the results of our analysis of the links between the course of the COVID-19 crisis and the valence of words. We saw that, overall, politicians responded to the crisis and the associated social anxiety with increases in word positivity. Perhaps most striking was the finding that word positivity could be significantly linked to COVID-19 case counts in a month-by-month analysis. We interpret these findings to reveal that lexical valence within parliament is a variable that is very finely and immediately attuned to changes in society.

\section{Future Opportunities}

Our finding that something as simple as single word valence can be used as a reliable metric in parliamentary speech opens up, in our view, new ways to compare individuals, groups and parties, and to compare times. The analysis of word valence also offers a potentially level playing field across parliaments in rather disparate countries. As we have noted in the introduction to this paper, Canada is but one of 25 countries that employ the Hansard system. In our view, the use of linguistic analyses in this domain could serve as a key tool in the understanding of those political systems and the societies that they represent. It is promising that, despite considerable methodological differences, our findings largely align with those reported by Rheault et al. (2016). Considering that their approximations of valence relied entirely on textual context and ours entirely on context-independent ratings, the alignment of these findings speaks to the validity of both methods. It also suggests that a future method combining both context-dependent and context-independent valence measures may provide additional accuracy. 
This study relied on a fixed number of valence ratings collected prior to the pandemic. We strategically selected a span of time for analysis that would be as close as possible to the time at which the ratings were collected [plus and minus 8 years from Warriner et al. (2013)]. Nevertheless, it is important to bear in mind that language is always changing. In addition, it is also possible that the extraordinary lived experiences of Canadians during the pandemic could have shifted the emotional valence of particular words, such as mask, symptom, and vaccine in unpredictable ways. This seems to us to be a valuable topic for future investigation.

Our findings of the relationship between words spoken in Parliament and the development of events in the broader Canadian context, point to a perhaps unique property of this type of language corpus. Our results show that the measurable emotional properties of words used by Members of Parliament are affected by the immediate political dynamics in which they work. It may also be the case that they are influenced by the broader emotional dynamics within society as a whole.

In our view, the Hansard also offers a very promising resource for psycholinguists. It is a large corpus with special properties. Speaking turns in the House of Commons are far more structured than spontaneous speech produced in everyday life. They are likely also more deliberate, coherent, and focused. Moreover, the Hansard transcription procedures remove a number of features characteristic of natural speech (e.g., false starts, repetitions, etc.). Nevertheless, we see great potential for the Hansard to be used to understand lexical choices in language production and the means by which lexical choices relate to specific discourse conditions. Thus, The Hansard can be used to better understand the relation of parliamentary speech to political dynamics and social conditions across countries and over time.

\section{REFERENCES}

Carpuat, M. (2014). "Mixed Language and Code-Switching in the canadian Hansard," in Proceedings of the first workshop on computational approaches to code switching, Doha, Qatar, October 25, 2014, 107-115.

Caruso, D., Frohman, L., Kinsman, R., and Sutherland, R. (2015). Some Editing Required: Producing Canada's Hansards. Can. Parliament. Rev. 35 (2), 7-14.

Crossfield, E., and Damian, M. F. (2021). The Role of Valence in Word Processing: Evidence from Lexical Decision and Emotional Stroop Tasks. Acta Psychol. 218, 103-359. doi:10.1016/j.actpsy.2021.103359

Davis, C. P., Libben, G., and Segalowitz, S. J. (2019). Compounding Matters: EventRelated Potential Evidence for Early Semantic Access to Compound Words. Cognition 184, 44-52. doi:10.1016/j.cognition.2018.12.006

Feinerer, I., Kurt, H., and Meyer, D. (2008). Text Mining Infrastructure in R. J. Stat. Softw. 25 (5), 1-54. doi:10.18637/jss.v025.i05

Fraser, A., and Marcu, D. (2007). Measuring Word Alignment Quality for Statistical Machine Translation. Comput. Linguist. 33 (3), 293-303. doi:10.1162/coli.2007.33.3.293

Hansard Association of Canada (2021). About Us. Available at: https://www. hansard.ca/about_eng.html (Accessed May 25, 2021).

Harp, N. R., Brown, C. C., and Neta, M. (2020). Spring Break or Heart Break? Extending Valence Bias to Emotional Words. Soc. Psychol. Personal. Sci. 12, 1392. doi: $10.1177 / 1948550620972296$

\section{DATA AVAILABILITY STATEMENT}

Publicly available datasets were analyzed in this study. This data can be found here: https://www.ourcommons.ca/documentviewer/en/ 35-2/house/hansard-index.

\section{AUTHOR CONTRIBUTIONS}

All authors listed have made a substantial, direct, and intellectual contribution to the work and approved it for publication.

\section{FUNDING}

This research was supported by the Social Sciences and Humanities Research Council of Canada Partnership Grant 895-2016-1008 ("Words in the World").

\section{ACKNOWLEDGMENTS}

We wish to thank Abbie Coy for early discussions leading up to this research and Sarah Macdonald for her work in the early stages of this project. We thank Victor Kuperman for valuable comments on the manuscript draft.

\section{SUPPLEMENTARY MATERIAL}

The Supplementary Material for this article can be found online at: https://www.frontiersin.org/articles/10.3389/fcomm.2021.770497/ full\#supplementary-material

Imbir, K. K., Spustek, T., and Żygierewicz, J. (2016). Effects of Valence and Origin of Emotions in Word Processing Evidenced by Event Related Potential Correlates in a Lexical Decision Task. Front. Psychol. 7, 271. doi:10.3389/ fpsyg.2016.00271

Keuleers, E., and Marelli, M. (2020). "Resources for Mental Lexicon Research: A Delicate Ecosystem," in Word Knowledge and Word Usage: A Cross-disciplinary Guide to the Mental Lexicon. Editors V. Pirrelli, I. Plag, and W. Dressler (De Gruyter), 164-184.

Kousta, S.-T., Vigliocco, G., Vinson, D. P., Andrews, M., and Del Campo, E. (2011). The Representation of Abstract Words: Why Emotion Matters. J. Exp. Psychol. Gen. 140 (1), 14-34. doi:10.1037/a0021446

Kousta, S.-T., Vinson, D. P., and Vigliocco, G. (2009). Emotion Words, Regardless of Polarity, Have a Processing Advantage over Neutral Words. Cognition 112 (3), 473-481. doi:10.1016/j.cognition.2009.06.007

Kuperman, V., Estes, Z., Brysbaert, M., and Warriner, A. B. (2014). Emotion and Language: Valence and Arousal Affect Word Recognition. J. Exp. Psychol. Gen. 143 (3), 1065-1081. doi:10.1037/a0035669

Kurokawa, D., Goutte, C., and Isabelle, P. (2009). "Automatic Detection of Translated Text and its Impact on Machine Translation," in Proceedings of MT-Summit XII, Ottawa, Canada, 81-88.

Libben, G. (2020). "Psycholinguistics: The Study of Language Processing," in Contemporary Linguistic Analysis. Editors W O'Grady and J Archibald. Ninth Edition (Toronto: Canada: Pearson).

Levshina, N. (2015). How to Do Linguistics with R? Data Exploration and Statistical Analysis. Amsterdam, Philadelphia: Benjamins. 
Mechura, M. B. (2016). Lemmatization list: English (en) [Data file]. Available at: http://www.lexiconista.com (Accessed May 25, 2021).

Parliament of Canada (2021). Hansard-84 (April 20, 2021). Available at: https:// www.ourcommons.ca/DocumentViewer/en/43-2/house/sitting-84/hansard (Accessed February 20, 2021).

Rheault, L., Beelen, K., Cochrane, C., and Hirst, G. (2016). Measuring Emotion in Parliamentary Debates with Automated Textual Analysis. PLoS ONE 11 (12), e0168843. doi:10.1371/journal.pone.0168843

RStudio Team (2020). RStudio. Boston, MA: Integrated Development for R. RStudio, PBC. Available at: http://www.rstudio.com/ (Accessed April 10, 2021).

Ryan, P. M., Cukier, W., Thomlinson, N. R., and Devereaux, Z. P. (2009). “A Decade of Gun Control in Canada: Hansard Debate Then and Now," in Canadian Political Science Association Conference Ottawa, ON: Carleton University

Silge, J., and Robinson, D. (2016). Tidytext: Text Mining and Analysis Using Tidy Data Principles in R. JOSS 1 (3), 37. doi:10.21105/joss.00037

UK Parliament (2021). What Is Hansard? Available at: https://hansard.parliament. uk/about (Accessed August 9, 2021).

van Berkum, J. J. A. (2018). "Language Comprehension, Emotion, and Sociality: Aren't we Missing Something?," in The Oxford Handbook of Psycholinguistics. Editors S Rueschemeyer and G Gaskell (Oxford: Oxford University Press), 644-669.
Warriner, A. B., Kuperman, V., and Brysbaert, M. (2013). Norms of Valence, Arousal, and Dominance for 13,915 English Lemmas. Behav. Res. 45, 1191-1207. doi:10.3758/s13428-012-0314-x

Wickham, H., Averick, M., Bryan, J., Bryan, W., McGowan, L., François, R., et al. (2019). Welcome to the Tidyverse. J. Open Source Softw. 4 (43), 1686. doi:10.21105/joss.01686

Conflict of Interest: The authors declare that the research was conducted in the absence of any commercial or financial relationships that could be construed as a potential conflict of interest.

Publisher's Note: All claims expressed in this article are solely those of the authors and do not necessarily represent those of their affiliated organizations, or those of the publisher, the editors and the reviewers. Any product that may be evaluated in this article, or claim that may be made by its manufacturer, is not guaranteed or endorsed by the publisher.

Copyright (c) 2021 Gallant and Libben. This is an open-access article distributed under the terms of the Creative Commons Attribution License (CC BY). The use, distribution or reproduction in other forums is permitted, provided the original author(s) and the copyright owner(s) are credited and that the original publication in this journal is cited, in accordance with accepted academic practice. No use, distribution or reproduction is permitted which does not comply with these terms. 